amusing. For outsiders, Franks pencils in a deft, accessible guide to what is known about water, reveals how scientists communicate with each other and offers some serious and not-so-serious asides. Especially rich are the press reports Franks finds fault with popular magazines and newspapers for inflaming an already hot scientific debate.

Recognizing that it is easier to reconstruct history than to learn from it, Franks, nonetheless, attempts the exercise. One lesson is that since competition is the driving wedge behind science, the race for priority created the polywater episode; other bungles like it are inevitable, given enough money and freedom. But competition may not be essential. Other ways of getting results may be just as good, if not better. We know that there is an opposing tendency for investigators to collaborate, rather than beat each other to the punch. Competition, like polywater, may be merely an artefact of our times.

Robert Ubell is the American Publisher of Nature. During the "polywater years" he was Editor-in-Chief at Plenum, where both Felix Franks and B.V. Deryagin were his authors.

\title{
Enchaining the power of catalysis
}

\section{Herman Mark}

The Chain Straighteners. Fruitjul Innovation: The Discovery of Linear and Stereoregular Synthetic Polymers. By Frank M. McMillan. Pp.207. ISBN 0-333-25929-7. (Macmillan Press, London: 1981.) £17.

THE steady and slowly moving mainstream of science and technology is occasionally interrupted and enlivened by unexpected events which accelerate it and eventually change its direction into new and hitherto inaccessible domains. Popularly known as "breakthroughs", such drastic evolutions have, since the last war, occurred in mathematics through the advent of electronic computers, in physics as a result of nucleonics and laser optics and, probably best known, in the life sciences through the discovery of helices in the structure of proteins and of double helices in that of nucleic acids. This book relates in a captivating and intriguing manner the story of another breakthrough which occurred in the mid-1950s in organic chemistry and the closely related field of polymer science and technology.

It started in the late 1940s when Dr Karl Ziegler, then Professor of Organic Chemistry at the University of Halle on the Saale, became Director of the Max Planck Institute for Coal Research in West Germany. Ziegler, already a well known and distinguished scientist at that time, had worked for years on a family of substances at the border of inorganic and organic chemistry known as metallorganic compounds and had specifically concentrated his efforts on the alkyl derivatives of aluminium. One particularly representative member of this family, triethylaluminium, is a colourless, volatile liquid, highly flammable and even explosive, requiring extreme skill in its preparation and handling. But these problems, a consequence of its high reactivity, attracted Ziegler rather than deterred him; and his experimental virtuosity allowed him to dominate this field for a number of years. In the early 1950s he observed that ethylene could be added to triethylalum- inium in such a manner that hydrocarbon chains from 10 to 20 carbon atoms were obtained. Ethylene was, at that time, a readily available and inexpensive raw material of the petroleum industry and the resulting aliphatic chain compounds were valuable starting materials for detergents, emulsifiers and plasticizers. No wonder that several chemical companies - for instance, the Montecatini Company in Italy - started to negotiate with Ziegler about a joint evaluation of his invention. Evidently his new process was interesting and useful.

But the real sensation came a year later. As a result of a strange sequence of trial and error steps, Ziegler and his associates found that through the addition to the aluminiumalkyl of heavy metal salts ethylene could be rapidly transformed into linear, high molecular weight polyethylene. Even though there already existed a well established commercial process the ICI process - for the production of a non-linear and somewhat softer type of polyethylene, and even though a linear polyethylene - Marlex of the Philips Petroleum Company - was on the verge of becoming commercial, the Ziegler discovery acted like a bombshell. The complete novelty of the catalytic system, the mild conditions of the polymerization and the resulting simplicity of the equipment produced a rarely experienced rush of licences for the new process. Careful laboratory work with difficult materials, intuitive appraisal of unexpected results and energetic pursuit of all available avenues had created a new tool for the polymer chemist - the Ziegler catalysts and started a new and important branch of polymer technology.

But, to the delight and surprise of the reader, this is only part of the story of the book. Dr Giulio Natta, directing the Chemistry Department of the Polytechnic Institute of Milan, happened to be a consultant for the Montecatini Company and, in due course, became familiar with the existence of Ziegler catalysts. He applied

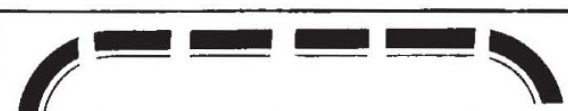

A Major Partnership in the Biosciences

Pitman Books and the Ciba Foundation, always in the forefront of scientific research

\section{Recent Titles}

\section{Development of the} Autonomic Nervous System: Ciba Foundation Symposium No.83 $\square$

Chairman: G Burnstock $229 \times 152 / 416 \mathrm{pp} /$ Cased/Illust/ISBN 027279619 0/Published July '81/ $£ 22.50$

\section{Microenvironments in Haemopoietic and Lymphoid Differentiation:} Symposium No.84 $\square$ (Held in honour of John Humphrey) Chairman: MF Greaves $229 \times 152 / 352 \mathrm{pp} /$ Cased/Illust/ISBN 027279636 0/Published August '81/ $£ 22.50$

Coming in December

The Fetus and Independent Life: Symposium No.86 $\square$ Chairman: G S Dawes

Brings together biochemists, physiologists and researchers interested in the development of endocrine control systems and the maturation of the CNS, to discuss how functional integration at birth is brought about.

$229 \times 152 / 384 \mathrm{pp} /$ Cased/Illust/ISBN $0272796506 / £ 22.50$

Order from your bookseller or, in case of difficulty, tick the titles required and send this advertisement with your cheque/postal order to:- Cashpost Service Book Centre, Southport, PR9 9YF.

Please send me the books I have ticked $\square$

Please send me details of all the Ciba Foundation Titles $\square$

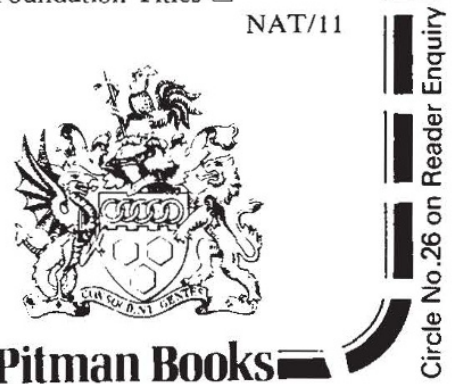




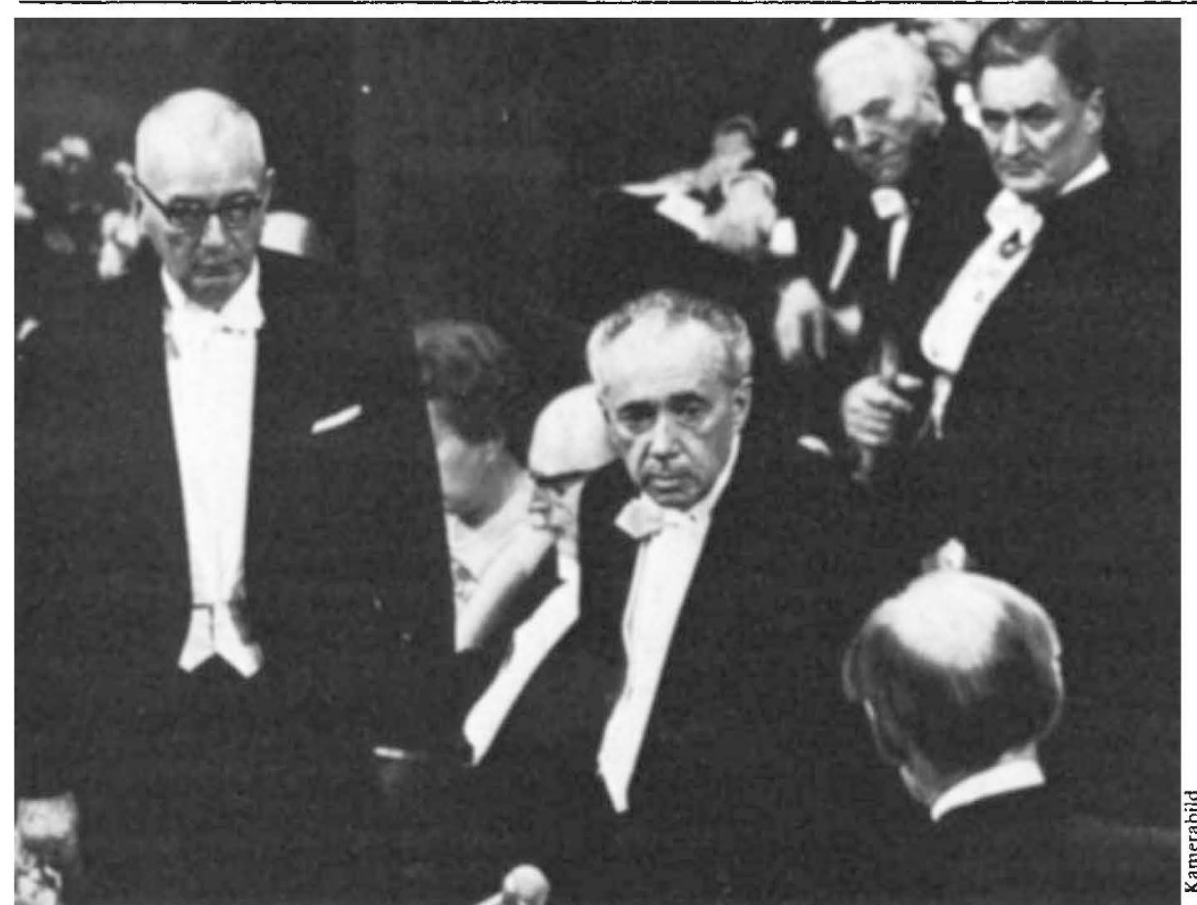

The Nobel Prize winners - Ziegler (left) and Natta listen as Professor Fredga makes the presentation speech, Stockholm, 1963.

them on propylene instead of on ethylene and, of course, obtained polypropylene. Considering that, at that time, no high polymers of propylene were known, this was an important contribution to polymer technology. It was dwarfed, however, by Natta's discovery that the use of Ziegler catalysts

\section{CRAHAMUERER OLD+RAREBOOKS}

78 Rosebery Road, London N10 2LA Telephone: $01-8838424$

\section{NATURE 1876-1914}

\section{COMPTES RENDUS 1858-1966}

LES PRIX NOBEL EN 1901-1975

LANATURE 1873-1934

(all substantially complete)

- Further details of these and other scientific journals on application.

- Regular catalogues of old and scarce books and journals in the History of Science, Technology and Medicine. Free on application.

- Visit our Science Department at "World of Books", 30 Sackville Street, London, W1.

- Serious collectors can inspect our stock of several thousand handpicked 16th-20th century volumes, by appointment, in North London.

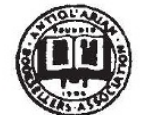

permitted the preparation of several species of polypropylene and other vinylpolymers differing from each other only by the steric arrangement of the substituents. Until that time stereospecific catalytic power had only been observed with natural enzymes: it is understandable, therefore, that the discovery of the existence of dozens of stereo-regulated polymers and their precise identification added to this commercial

\section{Gunther S. Stent}

The Double-Edged Helix: Science in the Real World. By Liebe F. Cavalieri. Pp. 196. ISBN 0-231-05306-1. (Columbia University Press: 1981.) $\$ 14.95, £ 10.80$.

THE latter-day metamorphosis of molecular biology from the esoteric speciality of a small band of aficionados into an academic juggernaut and billion-dollar industry, and its technical and moral implications, have not been slow to draw the attention of sociologists and ethicists of contemporary science. Indeed, the writing of books about the banishment of molecular biology from the Garden of Eden has become a minor cottage industry. The Double-Edged Helix by Liebe F. Cavalieri, a biochemist working at the New York Sloan-Kettering Institute for Cancer Research, is another contribution to this literature. Subtitled Science in the Real World, Cavalieri's book addresses the politics of the recent controversy surrounding the development of recombinant DNA technology. One of his chap- success a major scientific sensation.

Dr Frank McMillan, as a contemporary of all these events, was manager of a large industrial research laboratory and has, therefore, acquired a special feeling for the intricate relationship between fundamental research and practical application.

Needless to say, the alluring commercial features of the new catalysts and their novel applications attracted, with increasing intensity, the interest of many large companies. As a result of their permanent and strong participation, there came the day when the predominant question was formulated: "What belongs to whom?" a question which has been debated for the last 25 years. Understandably, the litigations have led to several confrontations, and in this domain the author is a true master of ceremonies, distributing fame and blame with restraint and distinction. All this makes excellent reading: entertaining, instructive and sometimes even philosophical. In several instances he offers specific warnings to avoid certain mistakes in research and development and even in the recording of results. The clarity of his exposition should certainly convince readers to avoid such mistakes in future. But, very probably, in doing so, they will make others.

Herman Mark is Dean Emeritus of the Polytechnic Institute of New York. At the time of the discoveries described in the book, he was in contact with two institutes in Germany and Italy and contributed some ideas to the mechanism of Ziegler-Natta polymerization.

\section{Jean Baptiste Rousseau revisited}

ters is entitled "Rousseau Revisited", and since Cavalieri makes no allusion to Jean Jacques, the philosopher, he appears to be revisiting Jean Baptiste, the poet, who was prosecuted and exiled from France in 1712 for libelling his colleagues.

As presented by Cavalieri, the situation is as follows. There are some people who believe that genetic engineering by recombinant DNA methods is dangerous and should be closely controlled. They are "thoughtful", "unusually frank" and "valiant"; they "have a conscience", "question neatly" and "testify" before government bodies "in the public interest". Other people, by contrast, believe that there is little or no danger in this enterprise and oppose strict controls on recombinant DNA research. They are "simplistic", "self-serving" and make "crusades"; they have "myopic vision" and form part of the "power structure", "smack of scientific elitism" and "lobby" before government bodies, "snowing", them with "massive campaigns" to satisfy "spurious", and "inane" needs. 